\title{
El conflicto y sus representaciones en el marco de la convivencia y la paz
}

\begin{abstract}
A partir de ahora, se da cuenta de los objetivos pretendidos en esta do las representaciones sociales que tanto docentes como estudiantes, en el marco de la práctica pedagógica, tienen de las competencias ciudadanas como parte de la labor de formación diaria a ejecutar en la escuela, entendida esta como el escenario propicio para tal actividad.

Es oportuno retomar el planteamiento de Navarro (citado en Piñero, 2008) cuando señala que "el sujeto individual es capaz de elaborar, de manera endógena, representaciones peculiares de la realidad social en la que habita, tanto en el nivel micro como en el macro". Navarro, igualmente sostiene que "el resultado de la relación mutuamente constituyente de ambos aspectos es un proceso morfo genético global que, en definitiva, configura al individuo como sujeto social. La subjetividad social del individuo, en efecto, no es otra cosa que el resultado dinámico de ese proceso" (p. 3).

Así las cosas, lo expresado por docentes y estudiantes de las instituciones educativas obedece a las representaciones peculiares de la realidad social en la que habitan tanto en el nivel micro, del aula de clase, como el nivel macro de sus ciudades, y el país, como señala Navarro, y son "el resultado de la relación mutuamente constituyente de ambos
\end{abstract}


aspectos es un proceso morfo genético global que, en definitiva, configura al individuo como sujeto social” (p. 3).

Cuando un docente afirma que, en el marco de sus estrategias pedagógicas, suspende intencionalmente la temática en la mitad de la clase y lo justifica argumentando:

Pero si usted logra que uno los calle, le trabajan. Y de pronto yo en la mitad de la clase, paro mi clase y echo mi chiste, y hay veces llevo mi guitarrita, $;$ Vamos a cantar! Profesor, ¿hoy no vamos a cantar? Esta semana no, la otra semana. Así los voy, los voy, llevando, pero al grupo hay que saberlo capotear. (PROF6GFD)

Esta forma de desarrollar la labor pedagógica se compagina con lo que Martínez Boom (1990) propone al mencionar que "la pedagogía ha alcanzado elaboraciones más o menos sistematizadas, ha desplegado teorías, elaborado nociones o simples objetos de discurso, configurándose como un saber independiente, aunque en íntima relación histórica...” (p. 3).

Y es perfectamente viable, en tanto es a través del discurso, con un sentido reflexivo, pero básicamente intencionado, que el docente, en este caso, logra su objetivo, el cual es llegar a sus estudiantes para que aprendan un conocimiento específico de acuerdo al área de desempeño que trabaja el docente.

Cuando Martínez Boom (1990) sostiene que se debe partir del reconocimiento de la pedagogía como una positividad que reflexiona sobre un conjunto de objetos de saber, entre ellos el saber pedagógico, se asume que alrededor de las representaciones peculiares de la realidad, según Navarro (citado en Piñero, 2008), la subjetividad social del individuo, en efecto, no es otra cosa que el resultado dinámico de ese proceso morfogenético global.

Para efectos de esta investigación, la representación peculiar de la realidad, en este caso, el desarrollo de las competencias ciudadanas en la práctica pedagógica, es de por sí un nuevo objeto de saber a ser verificado. 


\section{Comprensión y definición de conflicto}

El trabajo de investigación desarrollado en las instituciones educativas permitió establecer importantes hallazgos en torno al desarrollo de las competencias en las prácticas pedagógicas de sus docentes. Uno de los factores que se tuvo en cuenta fue el relativo a la concepción que sobre conflicto tenía la mencionada comunidad a nivel de docentes, ante lo cual señalaron que:

un conflicto pues es aquello que genera... que genera una diversidad de criterios, ¿`sí? Y lo que hace que de pronto se encuentren dos polos contrarios. Dos opiniones contradictorias completamente diferente la una a la otra entonces, eso genera un conflicto, por ejemplo. (DOC1EI)

Esta apreciación coincide con la postura de Bromme (1988) cuando habla de "unos conocimientos aplicables que deben por el contrario referirse a situaciones concretas, deben contener elementos normativos sobre objetivos que hay que alcanzar y deben precisamente evitar las generalizaciones y llenar de contenido concreto los conceptos abstractos que deban aplicarse" (p. 21), situación que se acopla en la medida en que los sujetos de investigación evidencian conocimientos aplicables a la definición de conflicto. En torno al tema señalado, los estudiantes, por su parte, consideran que:

Un conflicto tiene muchas... muchos por decirlo así muchas opciones. Está el conflicto físico, el conflicto verbal y el conflicto de ideas. El conflicto verbal es cuando uno sale de las casillas y dice groserías ataca a las otras personas no respetándolas, el físico es cuando uno se va a golpes y el de los pensamientos e ideologías yo digo que es cuando uno defiende su... lo que uno piensa, pero no se va... a las groserías, sino que uno da razones lógicas por las que está pensando eso. (E2EI)

Un conflicto para mí, o sea, no es como la gente lo entiende que un conflicto no tiene que ser que agarrarse a golpes y eso. Un 
conflicto puede ser verbal, puede ser físico, de manera psicológica también, y pues la verdad para mí un conflicto eh... no necesariamente tiene que ser eh... provocado por algo, o sea, o no tiene que irse directamente a un conflicto, sino que puede, puede esto... ser como un diálogo más bien como intentar buscar el diálogo en vez del conflicto. (E1EI)

Lo que se evidencia en el planteamiento del estudiante es el conocimiento que tiene sobre lo que para él es conflicto, lo cual se contrasta con la visión sobre el conocimiento que tiene el MEN, en este caso de "conflicto", en donde señala que "los conocimientos se refieren a la información que los estudiantes deben saber y comprender acerca del ejercicio de la ciudadanía". Como se observa aquí, conocimiento y comprensión del conflicto como parte del ejercicio natural de la ciudadanía, es perfectamente coherente. No obstante, el MEN considera que "si bien esta información es importante, no es suficiente para el ejercicio de la ciudadanía y se necesitan las demás competencias" (MEN, 2004, p. 12).

Partir de la comprensión que tienen los docentes cuando dicen "un conflicto pues es aquello que genera... una diversidad de criterios" y los estudiantes, cuando señalan "un conflicto tiene, por decirlo así muchas opciones", corrobora el planteamiento de Quezada (2004), quien dice que "los conocimientos entendidos como representaciones de la realidad (...) se construyen y acumulan según la formación y experiencia personal, están presentes en casi todas nuestras acciones, ya sean conocimientos elementales, complejos o de sentido común” (p. 70), mientras que Gonczi y Athanasou (1996) ofrecen la perspectiva de los conocimientos desde el profesional de la educación. En este sentido, toman como referencia la preparación típica del docente y mencionan tres aspectos: "desarrollo de un conocimiento general que se supone generalizable, desarrollo del conocimiento ocupacional y experiencia de trabajo" (p. 165).

La posición de los estudiantes E2EI y E1EI es concordante con el planteamiento de Chaux et al. (2004), cuando definen que "un ciudadano competente debe ser capaz de convivir con los demás de manera 
pacífica y constructiva". Tales autores, agregan que "esta convivencia no implica la armonía perfecta o la ausencia de conflictos". Los autores además sostienen que "esa perfección no es realista y tal vez ni siquiera sea deseable” (p. 19).

Los hallazgos también se acercan a la posición de Díaz-Aguado (2001) cuando sostiene que "para mejorar la convivencia educativa y prevenir la violencia es preciso enseñar a resolver conflictos (incluidos los relacionados con procedimientos de disciplina) de forma constructiva (...) y creando contextos normalizados, como las asambleas de aula" (p. 115). Este postulado equivale a que, aunque es normal que existan conflictos al interior del aula o fuera de ella, se debe dar un manejo adecuado para prevenir que progresen hasta llegar a niveles de agresión.

Considerando las referencias de Jares (2002), se identifica que "aprender a convivir significa conjugar la relación de igualdad y diferencia". Jares (1999b) dice que "las personas también somos diferentes por diferentes motivos y circunstancias; diferencias que pueden ser positivas y fomentadas y en otros casos diferencias que son negativas y por lo tanto deben ser eliminadas” (p. 118). Esto evidencia que la representación social que tienen en torno a la existencia de conflictos en este plantel educativo es entendida como la oportunidad de reconocer las diferencias y buscar alternativas de solución.

\section{Formas de generación de conflictos Justificación de acciones en un conflicto}

Un factor que contribuye a determinar las razones que originan las situaciones conflictivas en las instituciones está dado por las estrategias de reflexión de los docentes, cada vez que se presentan situaciones de confrontación de intereses, como lo explica este docente:

Siempre para hacer reflexión hay que estar preguntando constantemente. Entonces yo pregunto, por ejemplo: Eh... se llegó el caso de que un estudiante agredió a otro. Lo agredió. Entonces yo empiezo en vez de decirle no lo haga, le pregunto: ¿usted porque 
hace eso?... Justifíqueme ¿por qué usted hace eso? Y él empieza a hablar. ¿Cierto? Y a medida que él va hablando yo le voy preguntando. La respuesta que él me dé, me va generar una o dos preguntas y lo voy llevando a la reflexión. Es a través de la reflexión profunda de las cosas. Preguntando, ¿y usted por qué hace eso? ¿Usted cree que esta correcto lo que hizo? Ah, no. Pero dígame: ¿está correcto? Por ejemplo, ¿cierto? Entonces lo voy diciendo... Me dice que no, ¿por qué no está correcto? o ¿por qué sí está correcto?, ¿sí me entiende? Es la pregunta que lleva siempre la reflexión...o sea al muchacho lo meto en el cuento de que piense y que diga. (DOC1EI)

La descripción realizada por el docente, tiene similitud con la postura de Kattermann y Aramayo (2011), cuando reseñan que:

[...] los conflictos son inevitables, necesarios y pueden incluso ser beneficiosos al suscitar la innovación, la actividad, la identidad y la reflexión. Pero los beneficios dependerán de nuestra capacidad para manejar los conflictos, para resolverlos equitativamente e impedir sus manifestaciones violentas destructivas. (p. 16)

Estos investigadores plantearon el desarrollo de mecanismos institucionalizados para el tratamiento de los conflictos en el ámbito escolar y la construcción de convivencia pacífica en el Sistema Educativo Boliviano, sustentados en dos premisas:

La primera como Cultura de Paz en el proceso escolar, subcategorizadas a su vez como práctica de aula, por un lado, y como parte de la cultura institucional, por el otro. La segunda premisa, como Cultura de Paz desde la práctica cotidiana, la cual se sustenta en saberes y conocimientos, sobre la forma de analizar y comprender la realidad como requisito para transformarla, capacidades y habilidades, para gestionar los conflictos a través del diálogo y de mecanismos no violentos, y acción política y práctica de valores, 
entendidas como la toma de posición frente a la violencia, injusticia y otros. (p. 16)

No obstante, los estudiantes tienen diferencias frente a la justificación de los conflictos, en tanto señalan a los docentes como factores que contribuyen a la exacerbación de situaciones conflictivas. En el caso de este estudiante, su opinión gira en torno a que aprovechan su posición de poder frente a los estudiantes para imponer sus criterios, sin dar lugar a consensos.

Sí, porque hay maestros, hay maestros que se aprovechan en decir... yo siento eso, ¿no? que hay personas que se aprovechan, que porque son profesores llegan a imponer unas reglas como, como muy... desentonadas. O sea, uno esta acá y está acostumbrado a las normas de acá. De pronto llegó un profesor de otro lado y llegó como a levantar otras normas ahí. A hacer otras cosas y uno como que... se siente uno mal porque no está acostumbrado a eso. (AL2GFES)

Tales afirmaciones de los educandos, dejan ver que existen diferencias en la práctica frente a lo propuesto por García (1998), quien hablando de un aula pacifica consideró que "para crear una cultura de paz una tarea esencial es reorientar el aprendizaje y los procesos de socialización que sostienen la infraestructura psicológica de la violencia”, según lo planteado por Alzate (citado en García, 1998, p. 2).

García agrega que "mientras las culturas de violencia transmiten odio, la opresión de generación en generación, la cultura de paz cultiva la cooperación y la interdependencia: valores de igualdad, diversidad, justicia social y salud económica". Y subraya que "también cultiva normas, creencias y actitudes que apoyen la resolución de conflictos no violenta y la reconciliación. Aporta procesos de compromiso activos y realización espiritual que conduzcan a un cambio social positivo" (p. 2). 
En torno a la manera como se justifica la existencia de conflictos en el ejercicio de la práctica pedagógica, se logró captar una acción, como por ejemplo en la que en el aula de clase un "profesor reconviene a un estudiante porque habla con un compañero, mientras algunas compañeras del estudiante exponen” (G10).

Situaciones como esta se ajustan a lo planteado por William Kreider (citado en García, 1998), quien acuñó el término de "aula pacífica” en la década del setenta. Como ya se mencionó en líneas anteriores, este autor propuso que "para la consecución de todo esto proponemos caminar hacia la construcción de una escuela pacífica que descansa en varios principios que el profesor ha de cuidar mucho: $y$, entre otros, ofrecemos": primero, "desarmar la historia"; segundo, "expresión positiva de las emociones" y tercero, "resolución de conflictos".

Tanto docentes como estudiantes, al dar razones que justifican las acciones conflictivas, se sintonizan con los preceptos de Chaux et al. (2004), quien define las competencias cognitivas como las "capacidades para realizar diversos procesos mentales. En este caso, son capacidades para llevar a cabo procesos mentales que favorecen el ejercicio de la ciudadanía" (p. 21). Esto implica que al dar cuenta de los motivos se originan los conflictos, se da una toma de perspectiva. Es decir, se desarrolla la habilidad para ponerse mentalmente en los zapatos de los demás. Lograr acuerdos de beneficio mutuo e interactuar pacífica y constructivamente con los demás es, por ejemplo, mucho más probable si logramos comprender los distintos puntos de vista que tienen otros sobre una situación (p. 21).

\section{Estudiantes y profesores: actores en el conflicto escolar}

En el ejercicio cotidiano de la práctica pedagógica al interior de las instituciones educativas, se dan situaciones como la descrita por el docente:

A veces es con uno mismo. Entonces tiene el conflicto con el docente, y el muchacho se le ve en la cara que... que lo está mirando feo, que no le interesa la clase. Entonces, uno sabe que hay que 
hacer algo, porque ¡bueno! ese muchacho tiene algo conmigo: ¡vamos a solucionarlo! (PROF2GFD)

En este sentido, Galtung (citado en Chaux et al., 2004) ha planteado principios conceptuales como el de paz negativa: "entonces tiene el conflicto con el docente, y el muchacho se le ve en la cara que... que lo está mirando feo, que no le interesa la clase”, y paz positiva: "uno sabe que hay que hacer algo, porque ¡bueno! ese muchacho tiene algo conmigo: ¡vamos a solucionarlo!”, para referirse a los ideales de paz en una nación. Galtung opina que "mientras paz negativa se refiere a la ausencia de enfrentamientos violentos, paz positiva se refiere a la presencia de equidad e inclusión social” (p. 19).

Desde la perspectiva de Chaux et al. (2004), se sostiene que un ciudadano competente debe ser capaz de convivir con los demás de manera pacífica y constructiva, lo que no implica la armonía perfecta o la ausencia de conflictos. Incluso esa perfección no es realista y tal vez ni siquiera sea deseable, por lo menos así se percibió en el comportamiento de algunos estudiantes, mientras el profesor orientaba una de las clases como en el siguiente caso: "estudiantes no prestan atención al profesor; el profesor dice que si no atienden hace evaluación de una vez" (G200).

Referente a esta actitud observada en clase, es prudente retomar a Chaux et al. (2004), quienes también mencionan la necesidad de saber escuchar o tener una escucha activa, y la definen como la habilidad no solamente de estar atento a comprender lo que los demás están tratando de decir, sino también demostrarles a los demás que están siendo escuchados. Esto puede suceder de diversas maneras, por ejemplo, demostrando atención con el lenguaje corporal o evitando interrumpir a los demás mientras hablan. Otra de las maneras más efectivas para hacerle saber a los demás que están siendo escuchados es el parafraseo, que consiste en repetir en las propias palabras lo que los demás dicen para asegurarse que se está entendiendo correctamente lo que tratan de expresar (por ejemplo, usando expresiones como, “entonces, lo que me estás queriendo decir es que...”). 


\section{Estrategias de resolución: reflexión profunda}

\section{Identificación de conflictos entre estudiantes}

Los docentes hicieron referencia a la manera como logran identificar situaciones conflictivas entre sus estudiantes. Señalaron que en muchas oportunidades tales conflictos no son perceptibles a simple vista, sino que es necesario identificar posturas o actitudes de los alumnos en el aula de clase.

Yo creo que eso es uno. Pues para mí no... Uno siente es el ambiente pesado, cuando hay un conflicto. Entonces es que cuando uno llega y ve esa clase, porque al fin hay veces que uno no sabe qué es lo que está pasando. Porque ellos como que están en su mundo y... a veces lo tiene a uno como en un mundo aparte. (PROF5GFD)

Tal apreciación se puede entender desde el planteamiento de Goleman y Boyatzis (citados en Quezada, 2004) cuando hablan de la “diferencia entre competencias cognitivas y de razonamiento, competencias de Gestión de Relaciones y Capacidades de conocimiento y dominio Personal" (p. 68).

Según los autores, en situaciones como la narrada por el docente, se hace necesario relacionar el pensamiento analítico (proceso lógico de pensamiento que da una anticipada y única respuesta a una situación problemática), el pensamiento sistémico (entendido como un conjunto de herramientas que ayudan a comprender el mundo que nos rodea y en especial las interpretaciones que se producen entre las personas), el reconocimiento de los modelos, la experticia técnica o profesional, el análisis cuantitativo y la comunicación escrita (p. 68).

Lo manifestado por los informantes, además, cabe en la perspectiva de Perrenoud (citado en Rodríguez, 2004) cuando dice que competencia "sería la capacidad para actuar eficazmente en una situación definida, haciendo uso de los conocimientos, pero sin limitarse sólo a ellos”. Según tal consideración, "para hacer frente a 
una situación de manera óptima, en general se necesita hacer uso y asociar varios recursos cognitivos complementarios, tales como los conocimientos" (p. 70).

$\mathrm{Al}$ ser consultados sobre el mismo tópico, los estudiantes consideran que la identificación de conflictos entre sus compañeros pasa por reconocer las razones que lo generaron:

Pues yo lo primero que hago siempre cualquier pro... conflicto cualquier problema sea conmigo o con otro compañero, primero parar el conflicto mirar qué fue lo que paso si hubo un proble... e intentar solucionarlo porque o sea a mí me parece de mal gusto que peleen por cualquier cosa. Así que digamos que... Un ejemplo, que por ahí, que digamos un compañero dejó un lapicero, entonces llegó el otro y le escondió la tapa y que por eso se agarraron a pelear, hay que buscar... a mí me gusta mucho buscarle solución a los problemas y pues cada vez que yo vea que tenga un conflicto o que hay compañero que está en conflicto pues yo intento solucionarlo de la mejor forma posible y de acuerdo que ambos queden en igualdad en la solución. (E1EI)

Esta forma de develación de los conflictos puede justificarse desde la postura de Kanungo y Misra (citados en Agut y Grau, 2001), quienes se habían referido a las competencias cognitivas como las "capacidades intelectuales que permiten realizar actividades cognitivas genéricas (tareas no programadas, no rutinarias, dependientes de la persona y que se dan en un entorno complejo)". Grau y Agut sostienen que "se centran en la importancia para atender situaciones diferentes no programadas de antemano, que están más dirigidas por la persona que por la tarea en sí” (p. 5).

Dodge, Bates y Pettit (1990) explican igualmente esta forma de actuar de los estudiantes, cuando se refiere a otras competencias cognitivas, y las asocia con la capacidad para interpretar, imaginar, evaluar, considerar y cuestionar situaciones e intenciones de los actores y tomar decisiones objetivas (pp. 5-7): “ahora, respecto a lo que se observó en las aulas de clase, se pudo verificar algunas acciones tales como 
que: Estudiantes no prestan atención al profesor; el profesor dice que si no atienden hace evaluación de una vez (G10) [...] Profesor pide a una estudiante reubicarse, niña dice que no, se queda sentada en el lugar, el profesor no insiste y la dejó ahí. Sigue entregando la evaluación para ser contestada" (G10).

$\mathrm{Al}$ respecto, Chaux et al. (2004) definen las competencias cognitivas como las "capacidades para realizar diversos procesos mentales. En este caso, son capacidades para llevar a cabo procesos mentales que favorecen el ejercicio de la ciudadanía” (p. 21). La forma de actuar del docente en este caso específico obedece a una toma de perspectiva, considerada como la habilidad para ponerse mentalmente en los zapatos de los demás. Lograr acuerdos de beneficio mutuo e interactuar pacífica y constructivamente con los demás. La identificación de conflictos entre estudiantes, puede además comprenderse desde la interpretación de intenciones, según Chaux et al. (2014), en la medida en que tanto docentes como estudiantes tienen la capacidad para evaluar adecuadamente las intenciones y los propósitos de las acciones de los demás. Cuando hay problemas en esta capacidad, se puede suponer erradamente que los demás tienen la intención de hacerle daño al otro, inclusive cuando no hay suficiente evidencia para llegar a esa conclusión.

\section{Estrategias de resolución de conflictos}

Otro de los aspectos relativos a la manera de desarrollar las competencias ciudadanas en el ejercicio de la práctica pedagógica, independientemente de su área de dominio curricular por parte de los docentes, tiene que ver con la forma como ponen en práctica las estrategias para la resolución de conflictos en el aula. Ante situaciones como esta, los docentes consultados señalaron que:

Generalmente uno impone autoridad... Después, sí, de pronto hay una charla con ellos de reflexión, del comportamiento que están haciendo. Y que... o sea, repercute en los demás. Porque si ellos no dejan hacer nada los que si quieren hacer, son los que perjudican. Entonces generalmente uno es el que influye, o sea la autoridad. 
Entonces, la autoridad la hace uno mediante un grito; acomodarlos, sentarlos, ¡Bueno! (PROF1GFD)

Yo creo que lo primero para orientar a los estudiantes, es seguir los lineamentos del manual, ¿no? Para que todos hablemos el mismo idioma. Y segundo, dando ejemplo. Entonces pues nosotros no... no... no... salirnos de nuestros..., como de nuestros límites. Estar ahí, juiciosos con ellos, y en el momento en que se llega a presentar el conflicto, pues no alterarnos. Sino... por muy feo que sea, sino como que estar siempre como mediador, no..., ser el mediador ahí, intentando calmar a los muchachos. (PROF2GFD)

En este elemento entran en juego las habilidades emocionales de los maestros, como lo señalan Bisquerra y Pérez (2007), quienes sostienen que "la competencia emocional es un constructo amplio que incluye diversos procesos y provoca una variedad de consecuencias". En este orden de ideas, Salovey y Sluyter (citados en Bisquerra y Pérez, 2007) proponen cinco dimensiones básicas en las competencias emocionales: "cooperación, asertividad, responsabilidad, empatía y autocontrol".

Los autores indican que "estas dimensiones se solapan con el concepto de inteligencia emocional" y argumentan, como lo define Goleman (1995), que es preciso dividirlas en cinco dominios: "autoconciencia emocional, manejo de las emociones, automotivación, empatía y habilidades sociales" (p. 66).

Desde la óptica de los estudiantes, la manera más acertada de solucionar los conflictos está en la capacidad de sus compañeros para aconsejarlos cuando están pasando por situaciones difíciles:

La verdad yo a mí muchos, muchos de mis compañeros acuden a mí y me dicen sus cosas. O sea, sus problemas y pues la verdad yo les doy muchos consejos muchos consejos yo los ayudo mucho. Si yo los veo que puedo ayudar de manera, o sea, cómo le digo, o sea de manera, intervenir en el problema y ayudarlo pues si yo veo que si yo puedo lo puedo ayudar, pero la mayoría de veces a mí me llegan mis compañeros y me comentan problemas de ellos 
y todo. Pues yo los ayudo dándoles consejos y eso, y de manera digámoslo así, de manera sicológica los ayudo. (E1EI)

En este sentido, Saarni (citado en Bisquerra y Pérez, 2007) considera que "la competencia emocional se relaciona con la demostración de autoeficacia al expresar emociones en las transacciones sociales". Saarni ve "la autoeficacia como la capacidad y las habilidades que tiene el individuo para lograr los objetivos deseados. Para que haya autoeficacia se requiere conocimiento de las propias emociones y capacidad para regularlas hacia los resultados deseados” (p. 67). Para Bisquerra y Pérez (2007), desde esta perspectiva, toma relevancia la importancia del contexto: el espacio y el tiempo que son considerados como condicionantes de la competencia emocional (p. 67).

En la práctica pedagógica, lo que se observó en el aula de clase es que los docentes acceden a separar a los actores en conflicto, de tal manera que los espacios físicos contribuyan a disminuir los roces: "Profesor reubica a una niña porque al parecer intentaba obtener información irregularmente de otra compañera (copiarse) (G200) [...] Profesor reconviene a un estudiante porque habla con un compañero, mientras compañeras exponen" (G200).

Con respecto a esta situación puede retomarse a Martín, Berrocal y Brackett (2008), quienes hacen referencia no solo a la necesidad de desarrollar competencias emocionales en los estudiantes, sino que consideran como fundamental incluir la formación de competencias emocionales en los profesionales del magisterio, en su proceso inicial de formación.

Por su parte, Chaux et al. (2004) consideran que proponen como estrategias de resolución de conflictos poner en marcha procesos como la identificación de las propias emociones, que consiste en la capacidad de reconocer y nombrar las emociones en sí mismo. Para esto, es importante poder reconocer los signos corporales asociados con las distintas emociones, saber identificar los distintos niveles de intensidad (como un termómetro) que puedan tener las emociones de los actores de conflicto y saber reconocer las situaciones que usualmente generan emociones fuertes en dichos actores. 
Adicionalmente, Chaux et al. (2004) se refieren al manejo de las propias emociones, es decir, que las personas sean capaces de tener cierto dominio sobre las propias emociones. Y señala que no se trata de hacer desaparecer las emociones, ya que eso no es posible ni deseable.

\section{El diálogo como herramienta principal}

Tanto docentes como estudiantes coinciden en que buscar soluciones a través de la vía del diálogo es la mejor forma de redimir los conflictos que se dan al interior de las aulas, ya sea entre estudiantes o entre estudiantes y docentes.

Pues profe yo le colaboro ahí, un poquito con eso. Resulta que ayer, estaba yo leyendo un artículo, de algo que se llama: reestructuración cognitiva, ¿no...? Y hablan de..., de eso. ¿Cómo solucionar los conflictos en los estudiantes? Es que los estudiantes vienen con unos pensamientos negativos, y la reestructuración cognitiva lo que hace es cambiar esos pensamientos negativos. Convertirlos en pensamientos positivos. Es más, esos pensamientos negativos son lo que hace que los muchachos vean conflictos internos constantemente.

Entonces, nosotros como docentes, ipues! O eso lo hacen los psicólogos, ¿no? sino, yo por casualidad me lo leí, y nosotros como docentes podemos, identificar los pensamientos negativos de los muchachos que pueden ser con la familia, con otros estudiantes... Identificarlos. Hacer que los muchachos reconozcan que tienen esos pensamientos negativos e intentar modificarlos. Entonces sí sirve el hablar. ¿Por qué? Porque hablando, identificamos lo que el muchacho está pensando, y... podemos intentar modificar el pensamiento que tienen. Entonces hay que... isi es necesario! me imagino que diría la psicóloga, ¿no? (PROF2GFD)

\section{$[\ldots]$}

Si también, también cuando por lo menos yo tuve un caso de un compañero me dijo que le ayudara que el profesor me o sea 
que le iba mal en esa materia y pues yo hice lo que pude vine y hable con el profesor y el muchacho le dejaron un trabajo y pues pudo recuperar. (E1EI)

Pero, así como hay profesores, que son así, o sea, complicados, también hay profesores que son muy diferentes en su manera de ser. O sea, porque, o sea, lo consideran a uno y uno puede hablar con ellos tranquilamente sin tener, algún... (AL2GFES)

En torno a estas formas de resolución de conflicto señaladas por los entrevistados, se evidencia lo anotado por Vilá (2003) al hacer referencia a los centros educativos escolares. Este autor explica que dichos estamentos representan un contexto diverso y multicultural, cada vez más rico y complejo. Agrega que estos recintos son privilegiados para promover unas relaciones humanas equitativas, basadas en una comunicación eficaz que facilite la convivencia entre sus miembros.

Vilá sostiene que "el desarrollo de Competencias Comunicativas Interculturales desde el marco escolar, puede ser la respuesta a muchos de los interrogantes que se plantean en muchas sociedades en la actualidad" (p. 2). Vilá considera que se puede conceptualizar la comunicación intercultural como la comunicación interpersonal donde intervienen personas con unos referentes culturales lo suficientemente diferentes como para que ello pueda causar alguna barrera importante que altere la eficacia comunicativa y, por tanto, afecte a las relaciones interpersonales entre los interlocutores. Para ello, es necesario estar preparadas y preparados mediante una serie de habilidades que puedan ayudar a preparar estas interacciones; es decir, que se desarrolle una cierta competencia comunicativa intercultural (p. 2).

Chaux et al. (2004) definen estas acciones identificadas en el colegio Santiago Apóstol como el "saber escuchar", lo que implica no solamente estar atento a comprender lo que los demás están tratando de decir, sino también demostrarles que están siendo escuchados. Explican además que otra forma como se evidencia en lo aportado por los informantes en las instituciones educativas es que existen maneras más efectivas para hacerle saber a los demás que están siendo escuchados. De tal manera que los demás pueden reaccionar señalando 
que sí es eso lo que están queriendo decir, o indicar que no y aclarar de nuevo su posición.

Según lo observado en las aulas de clase, entre muchas de las situaciones que pudieron haber sido objeto de conflicto se identificaron hechos como: "docente de inglés entra al salón y pregunta al profesor de matemáticas si los autorizó a salir, porque hay algunos interfiriendo la clase en otro salón, profesor se lamenta, sale a la puerta mira y regresa a su puesto (G202) [...] Luego llamado de atención, estudiantes guardan silencio y prestan atención. (Tema: Diálogo de paz en La Habana) (G202).

Estos comportamientos denotan que no se dan en su plenitud lo considerado por la el Ministerio de Educción Nacional (MEN, 2004) cuando se indica que "las competencias comunicativas son aquellas habilidades necesarias para establecer un diálogo constructivo con las otras personas". El MEN ejemplifica: "la capacidad para escuchar atentamente los argumentos ajenos y para comprenderlos, a pesar de no compartirlos. O la capacidad para poder expresar asertivamente, es decir, con claridad, firmeza y sin agresión, los propios puntos de vista" (p. 13). Lo que se evidencia, por lo menos en las acciones reseñadas, es que hay una cierta normatividad que los estudiantes acatan, pero no comparten del todo.

\section{Asertividad en la convivencia cotidiana}

Los docentes reconocen que al interior de las instituciones se han presentado conflictos que han derivado incluso en enfrentamientos de hecho entre los estudiantes. Pero con el trascurrir del tiempo, las diferencias se subsanan y los protagonistas de tales situaciones llegan a reconciliarse.

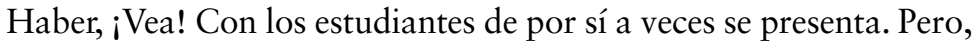
o sea, uno los ve que... a veces discutiendo. Cuando uno va en el momento a ver, ¿qué pasó aquí? ¡No! estábamos era jugando, estábamos a esto... Y cuando se presenta, es que si hay niñas que sí se han golpeado. Se han agarrado del cabello. A veces se han 
hasta arrancado, hasta el cabello. Entonces, se trata de solucionar y... unos días o de pronto unos meses, duran. Pero con los días y el tiempo, ellas vuelven a ser amigos, amigas otra vez. (DOC2EI)

Escenarios como el planteado por los docentes permiten inferir a partir de Chen y Starosta (citados en Vilá, 2003) que “desde el modelo de competencia comunicativa intercultural, se pretenden promover las competencias de los estudiantes para reconocer, respetar, tolerar e integrar las diferencias culturales, para de este modo estar preparados como ciudadanos y ciudadanas globales" (p. 3). De tal modo que, si bien es cierto que se dan los conflictos, por la vía del diálogo se logra la posterior reconciliación.

Entre tanto, Segovia et al. (2010) destacan que

[...] tras un periodo en el que la atención estaba centrada en el análisis de las variables estructurales (planificación, recursos, evaluación, etc.), el interés se ha desplazado hacia los procesos de interacción humana que tienen lugar en su seno y que explican buena parte del perfil que adopta el proceso docente en su funcionamiento. (p. 304)

De esta manera, se explica cómo en la medida en que el docente intervenga en la solución de las diferencias como facilitador del diálogo, los resultados de convivencia mejoran notablemente. A su turno, en relación con la manera como se pueden fijar posiciones frente a determinados temas, sin herir susceptibilidades, los estudiantes plantean casos como los siguientes:

¡No! Casi siempre, casi siempre ocurre eso, pues yo cuando digamos que estamos defendiendo un tema con mis compañeros yo les digo: Bueno, muchachos, les digo las cosas lo que yo creo que es... y pues cuando no les gusta a ellos pues, yo intento como mirar las cosas que esté acorde a todo. (E1EI)

Por ejemplo, hace poquito, una profesora, me dijo: juuuy...! Me vio cómo yo estaba vestida y me dijo: ¿̨usted de qué se disfrazó 
hoy? Entonces yo me quedé pensando... si le respondo con grosería no sería inteligente. Entonces... la dejé... Luego, después le dije: ¿y usted de qué se disfrazó hoy profesora? Me quedó mirándome así. No me dijo nada porque se acordó de lo que a mí me había dicho antes. Yo pensé que me iba decir algo, pero no me dijo nada. $\mathrm{O}$ sea, uno tiene que ser sereno frente a cualquier conflicto y pensar con cabeza fría... porque si uno piensa así, todo furioso y actúa mal, y la "caga". (AL3GFES)

Este relato es coincidente con la propuesta de Chaux et al. (2004), cuando llama a este tipo de actuaciones como asertividad, entendida como la capacidad para expresar las necesidades, intereses, posiciones, derechos e ideas propias de maneras claras y enfáticas, pero evitando herir a los demás o hacer daño a las relaciones.

Para Chaux, la asertividad es necesaria, por ejemplo, para poder manifestar un desacuerdo o responder ante una ofensa, de tal forma que los demás no se sientan agredidos. Muchos niños, niñas y adultos creen que frente a una ofensa solamente hay dos opciones: "dejarse" o responder agresivamente.

Ahora, desde lo observado en las instalaciones del colegio, en diferentes espacios más allá del aula de clase, se identificaron comportamientos tales como:

Un estudiante de undécimo, sale del salón se acerca coordinación, pregunta algo y regresa. A los 20 segundos sale una niña y regresa (OG-PJC). Coordinador recorre diferentes espacios en el colegio mirando que estudiantes permanezcan en las aulas. (OG-PJC)

Estudiante sale del salón de once, muestra un papel para salir, con permiso al coordinador. Este le responde que el papel es de ayer, le señala al rector y se acercan a hablar con él. (OG-PJC)

Este acontecer cotidiano es definido por Beltrán (citado en Segovia et al., 2010) "como el conjunto de habilidades que posibilita la participación apropiada del sujeto en situaciones comunicativas específicas”. 
Situaciones de convivencia, en donde se dan casos en los que alguna de las partes no está de acuerdo con alguna decisión tomada, pueden interpretarse desde el concepto de Reyzábal (2012), quien subraya que "para una comunicación eficaz deben tenerse en cuenta las costumbres sociales, los hábitos culturales y las variantes psicológicas propias de cada momento y circunstancia". La autora considera que "la competencia comunicativa suele incluir la lingüística, pero al ser más amplia (...) resulta fundamental para subrayar, negociar, intercambiar, reforzar o, incluso, negar significados que el mensaje verbal puede enunciar correctamente, pero, a veces, inadecuadamente" (p. 68).

\section{Manual de convivencia como ruta de acompañamiento}

Existen diferencias en la opinión que tienen tanto docentes como estudiantes frente al impacto que tiene el manual de convivencia en la solución de situaciones de conflicto. No obstante, se reconoce este documento como hoja de ruta para seguir procedimientos.

Dando una ruta guía, para... manejar esos conflictos. O sea, ¿qué se debe hacer en determinado caso? Y tener como... como... unas situaciones que se han detectado, y, y... para saber cómo manejarlas, y no perderse uno en el aula. Que no sé qué hacer con tal situación: que se... se... me presentó aquí en el aula. Para eso me imagino... que..., para eso... creo que es el manual de convivencia. (PROF5GFD)

Este relato permite identificar que, desde la perspectiva de los derechos humanos, las instituciones siguen una política pública, entendida como aquellas acciones dirigidas a mejorar la administración de un tópico nacional. Estas acciones deben ser orientadas por el Estado a través de las instituciones públicas y en el mejor de los casos deben ser apoyados por la comunidad beneficiaria, tal como lo sustenta (Lahera, 2004, p. 5). 
Tomando como referencia a Lahera (2004), puede señalarse que existen al menos dos conexiones entre las políticas públicas y los derechos humanos, al existir en las instituciones un manual de convivencia aprobado. Por un lado, se encuentran las posiciones que vinculan a las políticas y a los derechos humanos desde la óptica que señala que, si las primeras condensan la acción gubernamental y estatal, los segundos deben constituirse en su fundamento y en su fin, más aún cuando se trata de un Estado social de derecho cuyo mandato está sustentado en el respeto, la promoción y la garantía de los derechos humanos de sus ciudadanos. En este caso, de los miembros de las comunidades educativas de estos planteles educativos.

Entre tanto, al referirse al papel que juega el manual de convivencia como ruta de acompañamiento para la resolución de conflictos que permita una adecuada convivencia institucional, la posición de algunos estudiantes deja entrever que este instrumento sí ayuda:
Para mí, el Manual aporta mucho. Aporta mucho porque aquí bueno el trabajo que hace el coordinador me parece muy bueno porque él cada conflicto cada problema lo resuelve, lo soluciona de acuerdo a lo que diga el Manual de Convivencia y a mí me parece que el manual está haciendo un buen trabajo. A pesar de que necesita algunas modificaciones, pero está haciendo un buen papel en la convivencia del colegio. (E1EI)

Aunque otros, por el contrario, consideran que el manual no representa las oportunidades que debería tener el estudiante para solucionar adecuadamente sus conflictos:
Por ejemplo... acá... los profesores les hacen una anotación a un alumno, y yo leo el manual de convivencia. Dice que el alumno debe ser consiente y estar enterado de cuando le bajan el compor- tamiento o no. Y cuando llegan, y le dicen: ¡Bueno! Voy a leer- les los que perdieron el comportamiento y leen un montón: ¡No! ¿Pero yo por qué? Fue que yo nunca me di cuenta. ¿Qué paso? ¿Por qué perdí? (AL3GFES) 
A uno acá lo anotan sin uno darse cuenta y sin saber ¿por qué? Digamos: lo vieron en algo y lo anotan. Solo sabe al final del periodo que es que le dicen la nota. (AL4GFES)

Dice... que el alumno debe estar enfrente y debe firmar que consta que el comportamiento se le está bajando. Si no. No tiene por qué valerles... (AL3GFES)

¡Que por el pelo largo! (AL7GFES)

Por ejemplo, en el cabello de los hombres, en el manual de convivencia, ahí se dice de un corte adecuado más no... o sea... (AL5GFES) ¡Específico! (AL4GFES) ¡Sí! (AL5GFES)

Estas posiciones divergentes, desde la teoría de Chaux et al. (2004), permiten conocer que existe entre los estudiantes un importante nivel de pensamiento crítico que consiste en la capacidad para cuestionar y evaluar la validez de cualquier creencia, afirmación o fuente de información. De esta manera podemos cuestionar lo que ocurre en la sociedad e identificar cómo la realidad podría ser distinta a como es actualmente (pp. 21-22).

Esta manera de concebir la posición frente a un instrumento como el manual de convivencia, desde la perspectiva del Ministerio de Educación Nacional, deja al descubierto que las competencias cognitivas "se refieren a la capacidad para realizar diversos procesos mentales, fundamentales en el ejercicio ciudadano". De esta manera se ejemplifica, "la habilidad para identificar las distintas consecuencias que podría tener una decisión, la capacidad para ver la misma situación desde el punto de vista de las personas involucradas, y las capacidades de reflexión y análisis crítico, entre otras” (p. 12). En la práctica cotidiana, lo anterior se evidencia cuando se observan actos como este: "Coordinador pasa por pasillo del salón de undécimo y pide a un alumno que se meta el 'camibuso' en el pantalón: ¡Arréglese la camisa paisano!, le dice”. (OG-JPC)

Podría admitirse, como lo indica el MEN, que las competencias cognitivas se relacionan con el pensamiento analítico, el pensamiento sistémico y el reconocimiento de modelos. Esto implica la realización de 
operaciones mentales complejas como relacionar, recordar oportunamente, interpretar, asociar, inferir, tomar decisiones, inventar o encontrar soluciones a situaciones problemáticas de acuerdo a saberes específicos.

\section{Detonantes del conflicto Búsqueda del origen del conflicto}

Un elemento sobre el cual se indagó al interior de las comunidades educativas, objetos de esta investigación, estuvo relacionado con los factores que inciden en el inicio de los conflictos. En el caso de los docentes, consideran que la falta de interés por el currículo es una de las causas.

Y hay una cosa. Por ejemplo, en mi caso. En las matemáticas. Uno llega y el muchacho está viendo un tema, y el muchacho, no tiene bases, no tiene bases. ¡Se les olvidó! No sé... qué pasó con todo lo anterior. Entonces, uno ve que ahí ya... se frenó todo, porque uno ve... que el muchacho le entro como... internamente, como pereza. Le entró como desgano, le entró como desánimo. Entonces ya... uno empieza. ¿Pero, qué pasó? Y... para uno, a uno entra uno, en un conflicto interno acá. ¿'Sí? Entonces ya ellos, no... pierden el interés, y entonces de pronto, ya uno se echa a dormir, el uno se pone a molestar al otro, ya... pendiente de esas cosas. (PROF6GFD)

Desde la visión de Jares (2002), situaciones como la expuesta por el docente informante requieren de parte de los actores de la práctica pedagógica el "aprender a convivir (lo que) significa conjugar la relación de igualdad y diferencia". Jares (1999b) dice que "las personas también somos diferentes por diferentes motivos y circunstancias; diferencias que pueden ser positivas y fomentadas y en otros casos diferencias que son negativas y por lo tanto deben ser eliminadas" (p. 118).

La situación descrita al interior de la institución justifica también el postulado de Gimeno (citado en Jares, 2002), quien piensa que "los seres humanos son desiguales o diferentes en muchas cosas que los jerarquizan entre sí. Eso es diferente en ciertos casos, positivo en 
algunos e inaceptable desde un punto de vista ético de otro" (p. 118). Este autor agrega en este sentido que en cualquier caso factores como la diferencia o diversidad forman parte de la vida y pueden ser un factor natural de conflictividad (Restrepo, citado en Jares, 2002, p. 86).

Por su parte, los estudiantes señalan como parte del origen de los conflictos, las actuaciones de los docentes, frente a situaciones personales de los estudiantes que a su juicio no deberían ser intervenidas. En otros casos, los denominados juegos bruscos y los apodos entre compañeros constituyen otro factor que detona los enfrentamientos:

O... ¡Digamos! de algunas personas que tienen novia. O sea, digamos los hombres que tienen novia. Lo ven con la novia y le bajan comportamiento. ¡Si eso es normal tener novia! (AL4GFES)

Ahorita mucho conflicto lo ocasiona por los apodos, los apodos o sea como lo que estábamos hablando ahorita una persona normal está tranquila llega otro y lo ofende. También aquí se ha tomado el caso de que se esconde mucho las cosas de las personas. También hay muchachos que lo toman de verdad grave y comienzan a armar el conflicto a tratarse mal, a pelear físicamente y pues... (E1EI)

Según lo manifestado por los estudiantes, ver afectadas sus valoraciones de comportamiento en la institución permite sospechar que no existe en el marco de la práctica pedagógica de los docentes un ambiente adecuado al interior del aula. En palabras de William Kreider (citado en García, 1998), no se promueve adecuadamente un "aula pacífica”.

Al contrastar, lo expresado por docentes y estudiantes en torno al origen de los conflictos, con lo que se pudo observar en la cotidianidad de un día de actividades regulares de estudio, se logró captar situaciones como: "un estudiante es empujado por otro y cae al suelo, pero es jugando, varios estudiantes toman al que hizo caer y buscan hacerlo caer, pero es a nivel de juego" (G202).

Tales actuaciones, aunque pueden inicialmente no tener malas intenciones, no han sido previamente analizadas por los estudiantes desde la mirada de la consideración de consecuencias. Chaux et al. (2004) 
proponen que es infaltable considerar los distintos efectos que pueda tener cada alternativa de acción. Estas consecuencias pueden ser para sí mismo, personas cercanas, personas lejanas, o inclusive para animales o el medio ambiente. Dichas consecuencias pueden ser de corto o largo plazo. Por tanto, a juicio de Chaux y otros, "si consideramos las consecuencias de nuestras acciones, es mucho más probable que escojamos actuar de maneras que nos beneficien".

Adicionalmente, se refleja en los comportamientos de los estudiantes falta de formación en el desarrollo de la habilidad de empatía que consiste en la capacidad para sentir lo que otros sienten o por lo menos sentir algo compatible con lo que puedan estar sintiendo otros. Por ejemplo, alguien demuestra empatía si le duele que otras personas sufran o si se alegra con lo bueno que les pasa a otros. Este aspecto se da en el caso de los apodos que ocurren entre los estudiantes y que no alcanzan a ser controlados como fenómenos de origen de conflictos por parte de los docentes.

\section{Fallas en el seguimiento a procesos}

Otro factor descrito por los docentes como parte del origen de los escenarios de conflictividad en desarrollo de la práctica pedagógica está dado por las fallas en el seguimiento a los hechos que ocurren al interior de las comunidades educativas.

Yo pienso que porque no hay continuidad en los procesos que hacemos. Y no se le hace tampoco la evaluación a lo que vamos haciendo. Porque nosotros nos reunimos y hablamos y decimos, y todo se quedó ahí. No cumplimos lo que decimos. Entonces puede haber muchas ideas, y puede... ideas buenas, pero no las aplicamos, o la aplicamos un día y hasta ahí. No, no... seguimos. (DOC2EI)

Lo manifestado aquí deja ver en palabras de Beltrán (citado en Segovia et al., 2010) que existen debilidades en la dimensión comunicativa en razón a que los responsables de hacer seguimiento no tienen claro 
el factor comunicativo "entendido como el conjunto de habilidades que posibilita la participación apropiada del sujeto en situaciones comunicativas específicas”. Dicho factor es el que permite el éxito en cualquier proceso.

Además, desde lo propuesto por Tejada (2007), la dimensión comunicativa es un elemento importante puesto que "interesa como factor de motivación, como base para la toma de decisiones y como instrumento para el mantenimiento de un clima positivo en la comunidad educativa" (p. 3), sin embargo, en el estudio se hacen evidentes fallas significativas en esta dimensión.

Por su parte, los estudiantes sostienen que no existe un elemento fundamental a la hora de lograr la resolución de conflictos, como es escuchar al alumno antes de tomar cualquier decisión que lo afecte, según ellos, muchas veces de manera injusta.

Mucho. Yo he criticado muchas veces algunos estudiantes eh, docentes. Porque ellos no más implantan la ley, pero no... conversan con el estudiante que por qué fue el problema por qué está pasando eso. Yo creo que ellos deberían tener primero sus opciones: hablar con el estudiante, hacerlo reflexionar y luego si aplicarle el manual de convivencia. Que muchas veces, ¡sí! los estudiantes somos caspas, no los entendemos, pero ustedes a veces no nos entienden a nosotros. (E2EI)

Lo sostenido por los estudiantes deja ver que la falla en el seguimiento a los procesos pasa por una falta de saber escuchar, como lo plantea Chaux et al. (2004). Este autor señala que esta habilidad implica no solamente estar atento a comprender lo que los demás están tratando de decir, sino también demostrarles a los demás que están siendo escuchados.

Además, según los estudiantes, se les está quitando el derecho a la argumentación que, según Chaux, es la capacidad de expresar y sustentar una posición de manera que los demás puedan comprenderla y evaluarla seriamente. Según el autor, en una situación de desacuerdo entre dos o más personas, la argumentación les permite a los ciudadanos 
competentes comunicar sus ideas de tal forma que los demás no solo las entiendan, sino que inclusive puedan llegar a compartirlas, todo esto sin recurrir a la fuerza o al uso del poder (p. 23).

Por lo observado en estas dos situaciones, en las aulas de clase, se puede ratificar que existen fallas en el seguimiento a los procesos de resolución de conflictos: "otros estudiantes emiten sonidos 'aullidos', solo por pasar el tiempo mientras llega el docente de la clase siguiente (G202) [...] Una estudiante al final de la clase aborda al observador y le comenta acerca de un fraude hecho por dos estudiantes" (G201).

\section{Uso del celular: factor común en el conflicto escolar}

Un tercer elemento que constituye habitualmente origen de situaciones de alteración en la convivencia pacífica en los escenarios de la práctica pedagógica es la utilización del celular por parte de los estudiantes. Los profesores consideran que las actitudes, en algunos casos compulsivas, de los estudiantes a usar el celular todo el tiempo, alteran la convivencia.

Este en, en, décimo y en once, en caso puntual yo manejo sala de informática. Y es con los celulares porque ellos llegan ahí a robar Wi-Fi. ¿No? Señal de Wi-Fi. Y al principio de año yo no era sino: ¡Guarden esos celulares! ¡No profe! Espere que voy a descargar una cosa. Entonces dije: ¡Bueno! Ya me cansé de estar hablando de los celulares. Y más allá porque como tienen la red, quieren los que no tiene posibilidades de pagar un plan de datos, pues viven ahí pegados a la red. ¡Sí! ¡Sí! Y ustedes los han visto ahí. (PROF5GFD)

Por su parte, los estudiantes ven que la manera como los docentes les restringen el uso de sus propios dispositivos tecnológicos vulneran sus propios derechos.

Pues la verdad, la verdad más o menos, porque, o sea hay profesores que llegan y como le ven a uno el celular por fuera entonces 
se lo arrebatan y pues entonces el estudiante no le gustan y empieza el conflicto y que ¿por qué? Que haga el favor y que me lo devuelve y si no pues hay estudiantes que acceden a palabras mayores ya con los profesores. (E1EI)

Lo que se evidenció en una de las clases en que una estudiante manipulaba un celular mientras el docente estaba orientando la clase, es que las directivas efectivamente despejan de tales equipos a los estudiantes si los usan en momentos de clase: "coordinador ingresa con el rector y reconvienen a niña (estudiante) porque no quiso entregar celular, entra el rector y dice que le hagan la anotación y que no le permita ingresar a clase, hasta que la niña no traiga a su acudiente, niña en el momento no protesta" (G200).

El reiterativo conflicto entre docentes y estudiantes, originado por el uso del celular, bien podría explicarse desde la perspectiva de Coronado (2008), cuando señala que para construir una convivencia sana "es fundamental partir de la aceptación de que el conflicto es inevitable, porque solamente cuando se enfrentan y aprovechan las tenciones y confrontaciones propias del convivir es posible instaurar procesos de construcciones de una comunidad escolar pacífica” (p. 12).

En este punto, se hace necesario retomar a García (1998) cuando habla de la necesidad de generar una cultura alrededor de la convivencia pacífica. García considera que "para crear una cultura de paz una tarea esencial es reorientar el aprendizaje y los procesos de socialización que sostienen la infraestructura psicológica de la violencia”, según lo planteado por Alzate (citado en García, 1998, p. 2).

En definitiva, para sustraer del círculo vicioso de las confrontaciones por el uso del celular a las comunidades educativas estudiadas, bien podría tenerse en cuenta la necesidad de desarrollar la toma de perspectiva considerada por Chaux et al. (2004) como la habilidad para ponerse mentalmente en los zapatos de los demás. Lograr acuerdos de beneficio mutuo e interactuar pacífica y constructivamente con los demás, de tal manera que sea, por ejemplo, mucho más probable comprender los distintos puntos de vista que tienen otros sobre una situación. 
Chaux también considera en casos como este la necesidad de una generación de opciones para imaginarse creativamente muchas maneras de resolver un conflicto o un problema social. Sustenta esto en que varias investigaciones han mostrado que cuando esta competencia no está bien desarrollada las personas pueden recurrir más fácilmente a resolver las situaciones por la fuerza y la agresión porque no parecen contar con otras alternativas. Por lo menos así lo han reconocido los propios estudiantes de las comunidades educativas analizadas al sentirse impotentes frente a la pérdida, aunque sea parcial, de sus dispositivos tecnológicos.

\section{Consecuencias por inadecuado manejo de conflictos \\ Manual de convivencia desactualizado}

El trabajo de investigación sobre las representaciones sociales de docentes y estudiantes alrededor de las competencias ciudadanas en las prácticas pedagógicas de las instituciones educativas, pasa por un manual de convivencia considerado como desactualizado para atender las situaciones que a diario ocurren en el establecimiento. Así lo confirman los docentes quienes al referirse a este instrumento señalan:

Yo pienso que porque no hay continuidad en los procesos que hacemos. Y no se le hace tampoco la evaluación a lo que vamos haciendo. Porque nosotros nos reunimos y hablamos y decimos, y todo se quedó ahí. No cumplimos lo que decimos. Entonces puede haber muchas ideas, y puede... ideas buenas, pero no las aplicamos, o la aplicamos un día y hasta ahí. No no... seguimos. (DOC2EI)

Demasiada flexibilidad. Entonces, cuando se es demasiado flexible se puede, se puede... aquí se ha caído, yo considero: aquí se ha caído fácilmente en la en la... en una tolerancia y alcahuetería. Entonces eso ha hecho que... los conflictos en vez de disminuir, como que tiendan a crecer. (DOC1EI) 
Porque como no pasa nada, o sea, me parece a mí que es cierto que la democracia es buena. ¡Y es buena! Yo me considero demócrata, pero también los principios de autoridad no se pueden perder. Cuando se empieza a perder el principio de autoridad es porque se confunde la alcahuetería con la tolerancia. (DOC1EI)

Esta posición ideológica de los docentes contrasta con la perspectiva de los estudiantes, quienes por el contrario consideran que el manual de convivencia parte de unos criterios demasiado rígidos e intransigentes:

Por ejemplo, en el cabello de los hombres, en el manual de convivencia, ahí se dice de un corte adecuado más no... o sea... (AL5GFES) ¡Específico! (AL4GFES) ¡Sí! (AL5GFES).

Yo creo que cada quien es libre de cargar sus cosas y no creo que una manilla, vaya afectar el nivel de conocimiento de los alumnos si... O sea, usted entró con una manilla, ¡listo! una manilla. Pero no... La vez pasada tenían esa modalidad... (AL2GFES) ¡Sí! no afecta, el nivel académico ni su forma de pensar, ni nada de eso, por simplemente usar una manilla. (AL1GFES)

Ahí empiezan los conflictos. (AL7GFES)

En la observación no participante se pudo captar una forma de actuar de un docente y un estudiante a propósito de las normas establecidas en el manual de convivencia: "profesor pide celular a un alumno, él se lo entrega y se reubica y se nota un poco molesto" (G202).

Tales diferencias de opiniones relativas a la consideración que se le da a los criterios de aplicación de las normas vigentes en el manual de convivencia pueden entenderse desde la mirada de Arellano (2007), quien considera que "es un hecho que la violencia está en las escuelas y que tiene dos vertientes, una estructural que se manifiesta en la exclusión de la población de niños y adolescentes de un proceso educativo que brinde una calidad de vida" (p. 42).

Sobre la dualidad de apreciaciones en torno a la forma de interpretación del manual de convivencia en las instituciones es válido hacer 
notar a Arellano (2007) cuando deposita en el docente una alta responsabilidad en su función al afirmar que el "docente no está modelando el carácter social del educando para formarlo como un ciudadano que practique los valores de convivencia y que ejerza su autonomía con respeto por el otro".

En este sentido, la autora piensa que este hecho termina "incidiendo en la generación de una violencia directa, que como se ha planteado, está presente en las instituciones educativas y en sus contextos". Arellano concluye "que existe la urgente necesidad de transformar al docente y al alumno, (...) donde se tenga como meta aprender a vivir juntos” (p. 42).

\section{Conflictos entre docentes, influyen en los estudiantes}

Otras situaciones que se identificaron en el marco de la práctica pedagógica en las instituciones está relacionada con los conflictos que directa o indirectamente se dan entre los docentes, los cuales terminan influyendo en el comportamiento de los estudiantes.

Entonces el profesor... llama a la titular. Pero entonces, ella buscó al rector y se fueron para... para el salón. Entonces lo que yo veo: los muchachos le dijeron al rector otra cosa, y el rector le creyó a los muchachos. ¡Nooo, profesor! profesor, nosotros estábamos aquí. Nosotros queríamos clase. Nosotros estábamos atentos y él se fue. $\mathrm{Y}$ entonces como tiene ese problema con el profesor, entonces el rector le dijo a la titular: ¡No! Déjelo que él solo resuelva ese problema. (DOC2EI)

Por su parte, los estudiantes, señalan que los docentes en ocasiones son autoritarios y no permiten que el estudiante pueda expresarse:

Los que son así. Uno les dice: pero profesor, la otra profesora, es diferente. Ella, ella... está de acuerdo en esto. ¡De malas! Eso es problema de ellos. Esta es mi materia y yo hago lo que se me dé 
la gana con mi materia. Ellos que hagan lo que se le dé la gana con la de ellos. Le dicen a uno así. (AL3GFES)

Por lo mismo abusan como del poder. ¡Bueno! y si yo soy el profesor y le quiero colocar uno, se lo coloco y ¿usted qué va a hacer? (AL2GFES)

En uno de los momentos de clase observados, se captó que un docente pidió a un estudiante moverse hacia otro lugar del salón sin una razón aparente: “profesor organiza salón ubicando a los estudiantes, una estudiante pregunta por qué la reubicación, el profesor responde: Porque yo quiero que este aquí” (G200).

Lo que se puede evidenciar tanto en las acciones de docentes y estudiantes, como en las percepciones que hay en ambos actores, es que, en algunas de sus actuaciones, pasa por alto la dimensión emocional al no poner en práctica la consideración de consecuencias, según lo proponen Chaux et al. (2004). En lo investigado se descubre que no existe en algunos de los docentes y estudiantes la capacidad para considerar los distintos efectos que pueda tener cada alternativa de acción.

Según Chaux et al. (2004), dichas consecuencias pueden ser de corto o largo plazo: "Si consideramos las consecuencias de nuestras acciones, es mucho más probable que escojamos actuar de maneras que nos beneficien a todos: tanto a nosotros mismos, como a quienes puedan verse afectados por nuestras acciones" (p. 21). Comportarse de manera distante a esta dimensión emocional genera, como se lee en los testimonios, un impacto negativo en la formación de los estudiantes.

Respecto de esta situación, es oportuno mencionar a Saarni (citado en Bisquerra y Pérez, 2007), quien considera que "la competencia emocional se relaciona con la demostración de autoeficacia al expresar emociones en las transacciones sociales". Saarni ve "la autoeficacia como la capacidad y las habilidades que tiene el individuo para lograr los objetivos deseados. Además, piensa que para que haya autoeficacia se requiere conocimiento de las propias emociones y capacidad para regularlas hacia los resultados deseados" (p. 67), hecho que, por lo indagado, no ocurre con la eficiencia necesaria al interior de las instituciones. 


\section{Fragilidad institucional en la aplicación de normas}

Otra consecuencia generada por la forma inadecuada en el manejo de conflictos tiene que ver con la fragilidad institucional que permea a los actores involucrados en el transcurrir cotidiano, según la posición de algunos docentes.

Porque yo pienso que... Es que aquí... años atrás eh... Una vez, eh... dos muchachos que por armas algo así, no recuerdo bien, eh... se les propuso que al año siguiente no los recibían. Se les propuso. Ellos terminaron el año. No recuerdo cuál fue el problema: fue por armas, sí. Pero no recuerdo. En todo caso, que el año entrante porque cambiaran de colegio. Bueno... entonces ellos fueron y demandaron, y ganaron la tutela. ¿Por qué? Entonces el abogado decía, que, porque ellos debieron haber salido desde el momento del problema, haberse suspendido del colegio. Pero no... ellos se dejaron terminar. Entonces aquí cuando se presenta una situación, entonces aquí vienen. Yo molesto los muchachos. Yo les digo: después no empiecen a buscar... buscan al parquero, el personero, al padre, al alcalde, para que vengan a abogar por ellos. Entonces no... nos da miedo. Y el coordinador es uno de los que dice: ¡no! Es que las tutelas, es que esto, es que aquello. Entonces, no se aplica. Yo lo veo más por ese lado. (DOC2EI)

Entre tanto, los estudiantes señalan que la falta de apropiación de la normatividad existente en el manual de convivencia por parte de sus compañeros contribuye a que se tomen decisiones que en ocasiones vulneran sus derechos.

Los profesores dicen lo que pasa es que ustedes los alumnos nunca leen el manual de convivencia. No saben qué derechos tienen. Por eso nosotros hacemos lo que queramos con ustedes. Un profesor nos dijo: a mí me lo dijo. Había varios que estaban ahí y como... no hacen nada... No se defienden. (AL3GFES) 
Algunos estudiantes sienten que ante situaciones que contravienen la convivencia escolar y que afectan la formación ética de sus compañeros, no se toman las medidas que deberían adoptarse: "una estudiante al final de la clase aborda al observador y le comenta acerca de un fraude hecho por dos estudiantes" (G201).

Desde la perspectiva de Chaux et al. (2004), las indecisiones que se perciben en los testimonios de docentes y estudiantes sobre cómo actuar frente a determinados conflictos evidencian que la habilidad de la "metacognición" concebida como la capacidad para mirarse a sí mismo y reflexionar sobre sus debilidades y fortalezas, es precisamente uno de los factores que contribuye a que las instituciones sean frágiles desde el punto de vista del desarrollo de las competencias ciudadanas.

Por ejemplo, observar lo que uno hace, piensa o siente. Esta capacidad es fundamental para la ciudadanía, ya que permite tener un manejo de sí mismo, identificar los errores que uno comete en la interacción con otro y corregir el comportamiento propio, según Chaux. Esto es lo que precisamente no ocurre en forma adecuada, por lo que se palpa que no existe institucionalmente una política sólida para buscar la solución adecuada a los conflictos (p. 25).

Otra postura desde la cual se puede identificar esta fragilidad, es la de Cendales (2010), quien sostiene que "hoy se cree que el desarrollo emocional es decisivo por cuanto proporciona las herramientas para lograr una vida más placentera y constructiva con los demás” (p. 6). Enfatiza en que quien posee suficiente desarrollo emocional (entiéndase inteligencia), puede integrar las demás capacidades (cognitivas, comunicativas, emocionales).

Esto implica que poner en práctica tales habilidades, según Cendales, haría que los docentes que trabajen en desarrollo emocional sean muy apreciados por los estudiantes y su trabajo sea reconocido como digno de alabanza y reconocimiento (p. 6). Esta percepción refiere la importancia de los educadores en el papel que tienen para desarrollar competencias integradoras a sus estudiantes.

Así las cosas, en la medida en que haya desarrollo emocional que proporcione las herramientas para lograr una vida más placentera y constructiva, se podrán tomar decisiones más coherentes con la normatividad existente, a partir de la autorreflexión, lo que redundaría 
en el fortalecimiento del colegio para mejorar sensiblemente la convivencia y la paz y por ende fortalecer la institucionalidad.

\section{Representaciones de participación y responsabilidad democrática}

En la búsqueda de identificar las representaciones sociales que tienen docentes y estudiantes de las competencias ciudadanas en la práctica pedagógica, ahora en el ámbito de la participación y la responsabilidad democrática, es prudente tener en cuenta a Ilvento (2005), quien sostiene que "la realidad es objetiva, con características y propiedades que podrían ser descritas de modo que puede verse a la realidad tal cual es". Sin embargo, anota "que, a partir de los intereses, de las trayectorias, de las expectativas personales y culturales, de las posiciones y la intencionalidad, puede reconfigurarse una realidad que permite traducirse, en una realidad subjetiva" (p. 118).

Para Ilvento, la teoría de las representaciones sociales significa un modo de abordar la construcción social de la realidad, haciendo posible la existencia paralela de las dimensiones cognitivas y sociales de esa construcción, lo que facilita ir "mucho más allá de las opiniones o de las simples imágenes o reproducciones de la realidad externa” (p. 122).

A su turno, Pievi y Echaverry (2008) afirman en su estudio que "si el conocimiento cultural es el resultado de una construcción social, esto es porque el sujeto en la constante interacción con las otras personas va tejiendo una red de significados que le permite relacionarse en dicho contexto sociocultural" (p. 7).

Para asociar las representaciones sociales de las competencias ciudadanas con la forma en que se desarrollan en el marco de la práctica pedagógica, es necesario tomar en cuenta los aportes de Zuluaga (citada en Martínez Boom, 1990), cuando explica que "el saber nos permite explorar desde las relaciones de la práctica pedagógica con la educación, la vida cotidiana de la escuela y el entorno sociocultural que lo rodea" (p. 5).

Zuluaga agrega que ese mismo saber pasa por las relaciones con la práctica política, hasta llegar a las relaciones de la pedagogía con 
la didáctica, su campo de aplicación y de articulación con los saberes enseñados; con las ciencias de la educación; con la historia de la educación y de la pedagogía que los historiadores de las ideas toman como historia de su progreso.

Esta autora (citada en Martínez Boom, 1990) suma a su postura que "al adoptarse el término saber para la pedagogía, se busca destacar la movilidad que brinda al investigador para desplazarse desde las regiones más sistematizadas hasta los espacios más abiertos que están en permanente intercambio con las ciencias humanas y otras disciplinas y prácticas” (p. 5).

Otro factor a tener en cuenta es el planteamiento de Barragán (2012), cuando señala: “¿Cuánto vale un profesor? Es la pregunta que a uno le gustaría hacerse de cara a las nuevas tensiones y exigencias de los sistemas de gestión de la calidad en educación” (p. 20). Antunes (citado en Barragán, 2012) sostiene que tal interrogante "lleva a reflexionar sobre el papel que deben desempeñar los maestros, ante los dinamismos -no siempre éticos y morales- de la sociedad actual" (p. 20). Barragán explica que en el "texto emerge una comprensión del maestro en la que se resaltan las cualidades de los sujetos en relación con sus prácticas pedagógicas; los buenos maestros son siempre buenas personas, en ello estriba su éxito" (p. 20).

Un factor adicional de la práctica pedagógica lo constituye la institución educativa entendida como un lugar o un espacio que se planteó en un momento histórico determinado como una institución que tenía como finalidad la enseñanza. En su explicación, Martínez Boom señala que, a partir de entonces (siglo XVIII), la práctica de la enseñanza tendió a generar un saber autónomo, tendió a convertirse en un “mecanismo administrativo" que adquiere características propias descargando a la familia, y, en cierta forma, al clero de aquellas funciones que antes estaban confundidas y mezcladas en una sola.

Así las cosas, se avizora en el trabajo de triangulación realizado en el marco de la investigación desarrollada en las instituciones educativas, que las representaciones sociales de las competencias ciudadanas hacen parte de una realidad objetiva (Ilvento, 2005) con características y propiedades que pueden verse como son en la realidad. Sin embargo, como anota Ilvento, tanto docentes como estudiantes no pueden 
evitar reconfigurarlas a partir de la realidad en la que se desenvuelven, siendo por tanto subjetivas.

Al enlazar este fenómeno con los planteamientos de Zuluaga (citada en Martínez Boom, 1990) cuando conceptualiza la práctica pedagógica como el saber que pasa por las relaciones con la práctica política, hasta llegar a las relaciones de la pedagogía con la didáctica, su campo de aplicación y de articulación con los saberes enseñados, se evidencia que los docentes buscan a través de su práctica pedagógica involucrar a sus estudiantes en un ejercicio pedagógico de prácticas políticas a partir de la participación y del ejercicio responsable de la democracia, interpretados estos desde sus propias comprensiones.

No obstante, como Zuluaga lo contempla, el término saber para la pedagogía, que busca destacar la movilidad que brinda al investigador (entiéndase docente-investigador en el aula) para desplazarse desde las regiones más sistematizadas hasta los espacios más abiertos que están en permanente intercambio con las ciencias humanas y otras disciplinas y prácticas, se queda corto; sobre todo, desde la visión de los estudiantes, dado que más que buscar espacios abiertos para el intercambio de acciones y concepciones entre las ciencias humanas en la búsqueda de una democracia real y efectiva, muchos docentes se quedan en posiciones cómodas de la representación puramente idealista de lo que debe ser la práctica democrática en el aula y no motivan una participación significativa, o por lo menos no de manera generalizada. 
